\title{
Eugenol and carvacrol attenuate brain D-galactose-induced aging- related oxidative alterations in rats
}

\author{
Ali H. El-Far ${ }^{1}\left[\right.$ - Hadeer H. Mohamed ${ }^{1}$. Doaa A. Elsabagh ${ }^{1} \cdot$ Shymaa A. Mohamed ${ }^{2} \cdot$ Ahmed E. Noreldin $^{3}$. \\ Soad K. Al Jaouni ${ }^{4} \cdot$ Abdelwahab A. Alsenosy $^{1}$
}

Received: 29 September 2021 / Accepted: 27 January 2022 / Published online: 19 February 2022

(C) The Author(s) 2022

\begin{abstract}
Aging represents the accumulation of progressive changes in a human being over time and can cover physical, psychological, and social changes. It is an oxidative stress-associated process that progresses with age. The antioxidant activity of either eugenol (EU) or carvacrol (CAR) for aging in rats induced by D-gal for 42 days was investigated in the current study using 10 and $20 \mathrm{mg}$ of EU/kg/day/orally, while CAR was supplemented by 40 and $80 \mathrm{mg} / \mathrm{kg} /$ day/orally. Biochemical, mRNA expression, and histopathological assessments of brain samples evaluated the oxidative alterations induced by D-gal and the protective role of EU and CAR. Results showed that D-gal was causing oxidative alternation of the brain that was recognized via upregulation of $p 53$ and $p 21$ mRNA expression levels, as aging markers and Bax mRNA expression level, as an apoptotic marker. Also, the results observed alterations in the levels of biochemical markers as creatine phosphokinase (CPK) and triacylglycerol (TAG), besides, enhancement of brain antioxidant capacity. Finally, these results compared with the groups treated with EU and CAR to observe that the EU and CAR potentially attenuate these aging-related oxidative alterations in a dose-dependent manner. Finally, we can conclude that EU and CAR supplementations are considered promising natural protective compounds that could delay aging and maintain health.
\end{abstract}

Keywords Aging $\cdot$ Apoptosis $\cdot$ Anti-aging $\cdot$ Eugenol $\cdot$ Carvacrol

\section{Introduction}

Aging is a progressive physiological change due to oxidative stress leading to a reduction in the functional potential over the entire adult life span (Davalli et al. 2016). An imbalance between oxidants and antioxidants causes oxidative stress,

Responsible Editor: Lotfi Aleya

\author{
Ali H. El-Far \\ ali.elfar@damanhour.edu.eg \\ Hadeer H. Mohamed \\ doctor.hadeer.98dr@gmail.com \\ Doaa A. Elsabagh \\ doaaelsabagh43@gmail.com \\ Shymaa A. Mohamed \\ shymaa.abdullah@alexu.edu.eg \\ Ahmed E. Noreldin \\ ahmed.elsayed@damanhour.edu.eg \\ Soad K. Al Jaouni \\ saljaouni@kau.edu.sa \\ Abdelwahab A. Alsenosy \\ dr_alsenosy_2010@yahoo.com
}

1 Department of Biochemistry, Faculty of Veterinary Medicine, Damanhour University, Damanhour 22511, Egypt

2 Molecular Biology, Molecular biology unit, Medical Technology Center, Medical Research Institute, Alexandria University, Alexandria, Egypt

3 Histology and Cytology Department, Faculty of Veterinary Medicine, Damanhour University, Damanhour 22511, Egypt

4 Department of Hematology/Pediatric Oncology, Yousef Abdulatif Jameel Scientific Chair of Prophetic Medicine Application, Faculty of Medicine, King Abdulaziz University, Jeddah 21589, Saudi Arabia 
reducing antioxidant ability and accumulation of reactive oxygen species (ROS), leading to oxidative cellular alterations in lipid, protein, and nucleic acids (Neki 2015). Exposure to toxins, the sun, harmful foods, pollution, and smoke can damage tissue due to ROS generation (Krafts 2010).

In nature, the main form of galactose is D-galactose (Dgal). Milk and dairy products are the primary natural source of galactose (Acosta and Gross 1995). Some fruits and vegetables like tomatoes, brussels sprouts, bananas, and apples also have free galactose (Gross and Acosta 1991). In addition, the lactose hydrolysate syrup, as a sweetener, has been intensively used in biscuits, confectionery, and some dairy desserts containing high galactose content (Williams 2003).

The D-gal-induced aging model has been widely used to study aging (Parameshwaran et al. 2010; El-Far et al. 2020b). Higher D-gal caused ROS and decreased brain antioxidant activity, brain senescence, and shortened the duration of life (Coelho et al. 2015). Also, during its metabolism, D-gal produces ROS and produces advanced glycation end-products (AGE) glycation products that eventually speed up the aging process (Bucala and Cerami 1992; Song et al. 1999).

Natural products have played a critical role in drug discovery, especially cancer and infectious diseases (El-Far 2015; El-Far et al. 2018, 2020a, b, 2021; Ashrafizadeh et al. 2020, 2021; Atanasov et al. 2021; Abadi et al. 2021; Mohsen et al. 2022). Eugenol (4-Allyl-2-methoxyphenol, EU) is a major phenolic component of clove oil (Eugenia caryophyllata) which has powerful antioxidant and radical-scavenging activities (Gülçin 2011). Another natural product is carvacrol (CAR), the phenolic monoterpenoid found in essential oils of oregano (Origanum vulgare), thyme (Thymus vulgaris), pepperwort (Lepidium flavum), wild bergamot (Citrus aurantium bergamia), and other plants (Sharifi-Rad et al. 2018). The high antioxidant activity of CAR is due to the hydroxyl group $(\mathrm{OH})$, linked to the aromatic ring (Mondal et al. 2021). The present experiment aims to assist the aniaging protective effect of EU and CAR in experimentally induced aging in rats' brains by D-gal.

\section{Materials and methods}

\section{Ethics statement}

The study was approved in response to "NIH Guide for the Care and Use of Laboratory Animals" by the Faculty of Veterinary Medicine Ethics Committee of Damanhour University, Egypt.

\section{Experimental design}

Fifty-six male Wistar rats between 90 and $110 \mathrm{~g}$ were housed in a standard laboratory conditions with a 12-h light/dark cycle and allowed to freely access food pellets (Table 1) and water. Rats were allocated into seven groups $(n=8$ per group). In the control group, rats were subcutaneously injected with physiological saline solution $(0.9 \%)$ daily. In comparison, the vehicle group was injected subcutaneously with physiological saline solution $(0.9 \%)$ daily and orally supplemented with olive oil daily. Rats in the D-gal group were injected subcutaneously with $200 \mathrm{mg}$ D-gal/kg body weight (B.W.) (Fan et al. 2017) dissolved in saline solution daily along with oral supplementation with olive oil. In the D-gal+EU10 group, rats were injected subcutaneously with $200 \mathrm{mg} \mathrm{D-gal} / \mathrm{kg} \mathrm{B.W}$. dissolved in saline solution daily and orally supplemented with EU by a dose of $10 \mathrm{mg} / \mathrm{kg} \mathrm{B.W}$. (Mateen et al. 2019) dissolved in olive oil (Yogalakshmi et al. 2010), while in D-gal+EU20 group, rats were injected subcutaneously with $200 \mathrm{mg} \mathrm{D-gal} / \mathrm{kg} \mathrm{B}$.W. daily dissolved in saline solution in addition to oral supplementation with EU by a dose of $20 \mathrm{mg} / \mathrm{kg}$ B.W. (Mateen et al. 2019) dissolved in olive oil (Yogalakshmi et al. 2010). Rats in the D-gal+CAR40 group were injected subcutaneously with Dgal (200 mg/kg B.W.) dissolved in saline solution daily plus oral supplementation with CAR by a dose of $40 \mathrm{mg} / \mathrm{kg} \mathrm{B}$.W. daily (Aristatile et al. 2009) dissolved in olive oil (Stojanović et al. 2019); on the other hand, in the D-gal+CAR80 group, rats were injected subcutaneously with D-gal (200/kg B.W.) daily dissolved in saline solution and orally supplemented with CAR by a dose of $80 \mathrm{mg} / \mathrm{kg} \mathrm{B}$. W daily (Aristatile et al. 2009) dissolved in olive oil (Stojanović et al. 2019). The experiment was spent for 42 days, and rats were weighed on day 42 .

\section{Sampling}

On day 42, the animals were anesthetized by isoflurane inhalation and euthanized by cervical dislocation. Blood samples were collected from rats' veins. After centrifugation at 1000 $\times \mathrm{g}$ for $15 \mathrm{~min}$ at room temperature, clear sera were separated, labeled, and subjected to biochemical analyses.

Brain samples of the cerebellum and hippocampus were collected after surgical removal then flushed with phosphate

Table 1 Ingredients of the basal diet

\begin{tabular}{ll}
\hline Ingredients & $\mathrm{g} / \mathrm{kg}$ diet \\
\hline Corn flour & 529.5 \\
Casein & 200 \\
Sucrose & 100 \\
Soybean oil & 70 \\
Cellulose & 50 \\
Mineral mix & 35 \\
Vitamin mix & 10 \\
L-cystine & 3 \\
Choline & 2.5 \\
\hline
\end{tabular}


buffer saline (PBS) to remove excess blood for histopathological, antioxidant parameters and mRNA expression assessment. Part of the brain samples was fixed in $4 \%$ paraformaldehyde dissolved in PBS for $48 \mathrm{~h}$ for sample fixation. Other parts were labeled and kept in $-80^{\circ} \mathrm{C}$ for antioxidant status and mRNA expression assessments.

\section{Biochemical assessment}

Serum samples were subjected to determination of total cholesterol (T.cholesterol), triacylglycerol (TAG), alanine aminotransferase (ALT, EC 2.6.1.2), aspartate aminotransferase (AST, EC 2.6.1.1), creatinine, creatine phosphokinase (CPK, EC 2.7.3.2), and lactate dehydrogenase (LDH, EC 1.1.1.27). Biochemical tests measured using Roche/Hitachi Cobas c 311, Cobas c 501/502 analyzers measured using the full automated system.

\section{Oxidative stress and antioxidant status assessment}

Oxidative stress and antioxidant biomarkers were analyzed in brain homogenate $20 \%(\mathrm{w} / \mathrm{v})$ using cooled $0.1 \mathrm{M}$ phosphate buffer saline and subjected to determination of malondialdehyde (MDA) and total antioxidant capacity (TAC) levels and the activities of glutathione peroxidase (GPx; EC 1.11.1.9) and glutathione S-transferase (GST; EC 2.5.1.18) using commercial Biodiagnostic Co. (Giza, Egypt) kits. Protein concentrations of brain homogenates were assessed with the Bradford assay (5000002, Bio-Rad Laboratories, Watford, UK) to standardize biochemical parameters (Bradford 1976).

\section{Gene expression assessment by real-time polymerase chain reaction (RT-PCR)}

According to the manufacturer's kit, total RNA was extracted from the tissue samples (Easy spin TM kit Total RNA Extraction Kit, INTRON Biotechnology, Korea). The purities and concentration of RNA were measured by A Nanodrop spectrophotometer (Genway Nanodrop, Germany). $1 \mu \mathrm{g}$ of RNA $(260 / 280$ ratio $=1.8-2.0)$ used for the transcription of cDNA using RT-Premix Kit (INTRON, Biotechnology, Korea.). $2 \mu$ of RT product were mixed with $10 \mu 1$ of SYBR-Green master mix (INTRON, Biotechnology, Korea) and $0.5 \mathrm{mM}$ of each forward and reverse primer (Table 2) and nuclease-free water in a final volume of 20 $\mu 1$. All reactions were performed on a 7500 Applied Biosystems, USA, with the following conditions: $95^{\circ} \mathrm{C}$ for 10 min, followed by 40 cycles at $95{ }^{\circ} \mathrm{C}$ for $15 \mathrm{~s}, 58^{\circ} \mathrm{C}$ for 15 ${ }^{\circ} \mathrm{C}$, and $72{ }^{\circ} \mathrm{C}$ for $30 \mathrm{~s}$. Relative expression of mRNA was normalized to $\beta$-actin as housekeeper gene. The fold changes of mRNA expression were calculated with the $2^{-\Delta \Delta \mathrm{Ct}}$ method described by Livak and Schmittgen (2001).

\section{Histopathological assessment}

After flushing with PBS (pH 7.4) and fixing in $4 \%$ paraformaldehyde dissolved in PBS for $48 \mathrm{~h}$, the fixed specimens were processed by the conventional paraffin embedding technique, which included the dehydration through ascending grades of ethanol, clearing in three changes of xylene and melted paraffin and finally embedding in paraffin wax at $65^{\circ} \mathrm{C}$. Four-micrometer thick sections were stained by hematoxylin and eosin (Bancroft and Layton 2013). Micrographs of the sections were taken with a digital camera (Leica EC3, Leica, Germany) connected to a microscope (Leica DM500).

\section{Statistical analysis}

A one-way ANOVA with Tukey's post hoc multiple range tests was used for the data analysis using a GraphPad Prism v.5 (https://www.graphpad.com/), accessed on 10 March 2021 (GraphPad, San Diego, CA, USA). All declarations of significance depended on $P<0.05$.

\section{Results}

\section{Body weight}

The body weight in the D-gal group was significantly decreased $(P<0.001)$ compared with the control group.

Table 2 Primer's sequence

\begin{tabular}{lllll}
\hline Genes & Primers $5 \rightarrow 3$ & Accession number & Tm & Product size \\
\hline$p 53$ & F: CCCACCATGAGCGTTGCT & NM_030989.3 & 60.36 & 116 \\
& R: CCACCCGGATAAGATGTTGG & & 62.46 & \\
$p 21^{\text {CIPI/WAFI }}$ & F: GACCTGTTCCACACAGGAGCAAAG & NM_080782.3 & 63.82 & 145 \\
& R: GTCTCAGTGGCGAAGTCAAAGTTC & & 62.07 & \\
\multirow{2}{*}{ Bax } & F: GCGAATTGGCGATGAACTG & NM_017059.2 & 57.78 & 216 \\
& R: ATGGTTCTGATCAGCTCGG & & 56.92 & \\
\multirow{2}{*}{-actin } & F: GCCGTCTTCCCCTCCATCGTG & NM_031144.3 & 65.10 & 358 \\
& R: TACGACCAGAGGCATACAGGGACAAC & & 65.85 & \\
\hline
\end{tabular}


On the other hand, in the D-gal+EU10 $(P<0.001)$, D-gal+EU20 $(P<0.01)$, D-gal+CAR40 $(P<0.01)$, and D-gal+CAR80 $(P<0.01)$ groups, the body weight exhibited a significant increase in comparison with the control group (Fig. 1).

In comparison with the vehicle group, the body weight in the D-gal+EU10 $(P<0.001)$ and the D-gal+EU20 $(P$ $<0.05)$ groups was markedly increased. Also, the body weight in the D-gal+EU10, D-gal+EU20, D-gal+CAR40, and D-gal+CAR80 groups exhibited significant increases $(P<0.001)$ in comparison with the D-gal group.

\section{Biochemical assessment}

The serum total cholesterol levels in the D-gal $(P<$ 0.01), D-gal+EU10 $(P<0.01)$, D-gal+EU20 $(P<0.01)$, vehicle $(P<0.001)$, D-gal+CAR40 $(P<0.001)$, and D-gal+CAR80 $(P<0.001)$ groups were significantly decreased compared with the control group (Fig. 2A).

The serum TAG levels in the D-gal group were significantly increased $(P<0.01)$ compared with the control group. Also, in the D-gal+EU10, its level exhibited a significant increase $(P<0.05)$ in comparison with the same group. TAG levels were markedly raised increased in Dgal $(P<0.001)$ and D-gal+EU10 $(P<0.01)$ groups in comparison with the vehicle group (Fig. 2B). Serum CPK activities in the D-gal group were significantly increased compared with the control $(P<0.01)$ and vehicle $(P<$ $0.05)$ groups. In the D-gal+EU20 and D-gal+CAR80, its

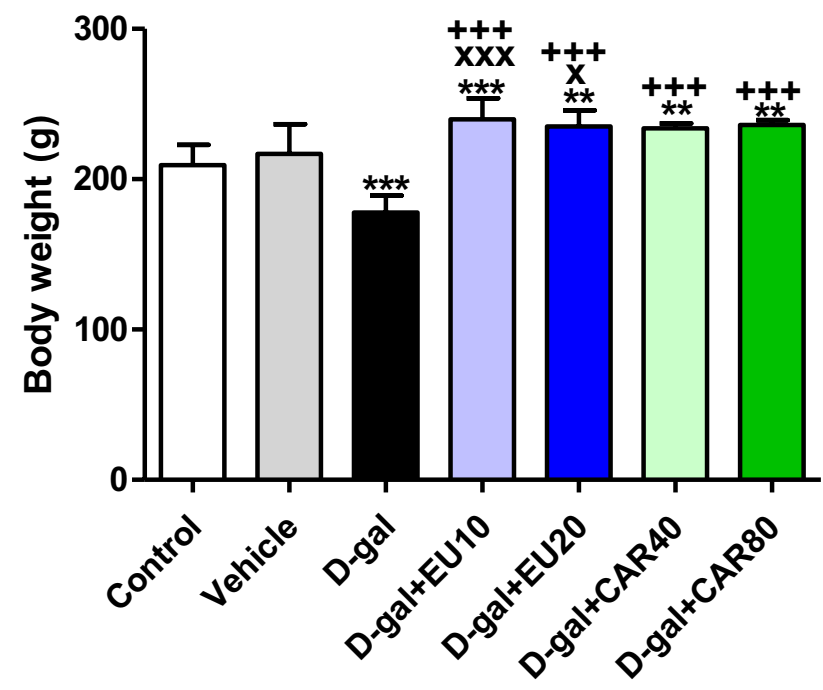

Fig. 1 Body weight. Data were analyzed with a one-way ANOVA followed by Tukey's multiple comparison test. ${ }^{* *} P<0.01$ and ${ }^{* * *} P<$ 0.001 vs the control. ${ }^{\mathrm{x}} P<0.05$ and ${ }^{\mathrm{xxx}} P<0.001$ vs vehicle. ${ }^{+++} P<$ 0.001 vs D-gal. Error bars represent mean \pm SD. $n=8$. levels were significantly decreased $(P<0.05)$ in comparison with the vehicle group.

\section{Oxidative stress and antioxidant status}

Induction of aging by D-gal significantly $(P<0.001)$ increased MDA (Fig. 3A), the product of oxidative stress, compared with control and vehicle groups. MDA levels in brain homogenates were significantly $(P<0.001)$ decreased in D-gal+EU10, D-gal+EU20, D-gal+CAR40, and D-gal+CAR80 groups compared with the D-gal group. TAC levels (Fig. 3B) GPx (Fig. 3C) and GST (Fig. 3D) activities were significantly increased in the same groups compared with the D-gal group to neutralize the oxidative stress process.

\section{Gene expression assessment by RT-PCR}

The brain $p 53$ mRNA expressions in the D-gal, D-gal+EU10, D-gal+EU20, D-gal+CAR40, and D-gal+CAR80 groups were significantly increased $(P<0.001)$ compared with the control and vehicle groups (Fig. 4A). Compared with the Dgal group, in the D-gal+EU10, D-gal+EU20, D-gal+CAR40, and D-gal+CAR80 groups, $p 53$ expressions were significantly decreased $(P<0.001)$.

On the other hand, its expression levels in D-gal+CAR40 were significantly raised $(P<0.001)$ compared with the D-gal+CAR80 group. In the D-gal+EU10 group, its level was a significant decrease $(P<0.001)$ in comparison with D-gal+EU20 and D-gal+CAR40 groups, while in the D-gal+EU20, its level showed a significant increase $(P<$ 0.001 ) compared with the D-gal+CAR80 group (Fig. 5).

Brain $p 21$ mRNA expression levels in the D-gal group were significantly increased $(P<0.001)$ compared with the control group (Fig. 4B). In the D-gal+EU10, D-gal+EU20, D-gal+CAR40, and D-gal+CAR80 groups, the expression levels were significantly decreased $(P<0.001)$ compared with the D-gal group. In the D-gal group, its levels showed significant increases $(P<0.001)$ compared with the vehicle group, while its levels were significantly decreased ( $P$ $<0.001)$ in D-gal+EU10, D-gal+EU20, D-gal+CAR40, and D-gal+CAR80 groups compared with the vehicle group.

The brain Bax mRNA expression in the D-gal group was significantly increased $(P<0.001)$ compared with the control group. On the other hand, in the D-gal+EU10, D-gal+EU20, D-gal+CAR40, and D-gal+CAR80 groups, its expression levels were significantly decreased $(P<$ 0.001) in comparison with the control group. Also, the Dgal group was exhibited significant increases in Bax expression levels $(P<0.001)$ compared with the vehicle group (Fig. 4C). In the D-gal+EU10, D-gal+EU20, D-gal+CAR40, 
Fig. 2 Biochemical assessment of serum A total cholesterol (T.cholesterol), B triacylglycerol, $\mathbf{C}$ alanine aminotransferase (ALT), D alanine aminotransferase (AST), $\mathbf{E}$ creatinine, $\mathbf{F}$ creatine phosphokinase (CPK), and $\mathbf{G}$ lactate dehydrogenase (LDH). Data were analyzed with a one-way ANOVA followed by Tukey's multiple comparison test. ${ }^{*} P<0.05,{ }^{* *} P$ $<0.01$, and ${ }^{* * *} P<0.001$ vs the control. ${ }^{\mathrm{x}} P<0.05,{ }^{\mathrm{xx}} P<0.01$, and ${ }^{\mathrm{xxx}} P<0.001$ vs vehicle.

Error bars represent mean \pm SD. $n=7$.
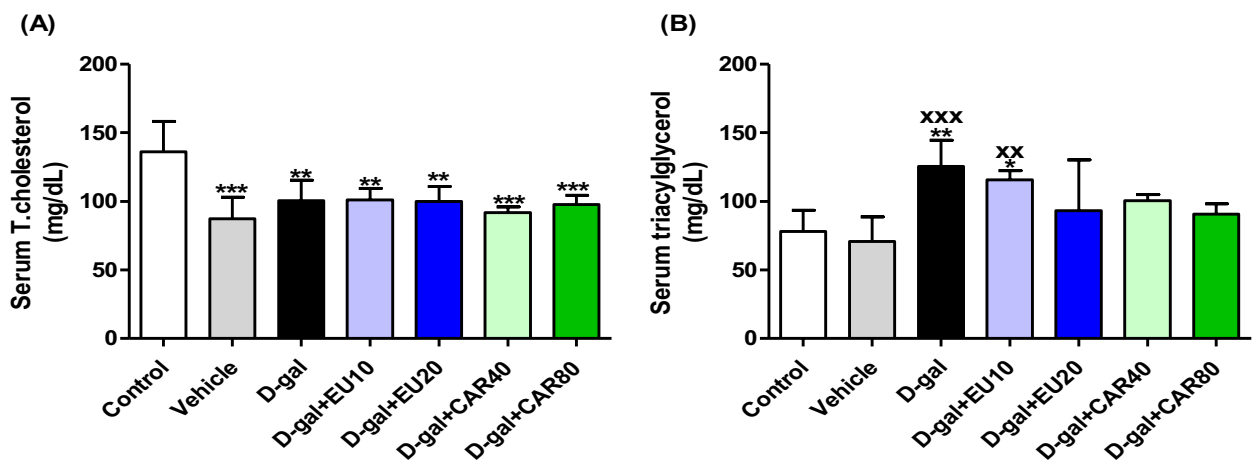

(C)

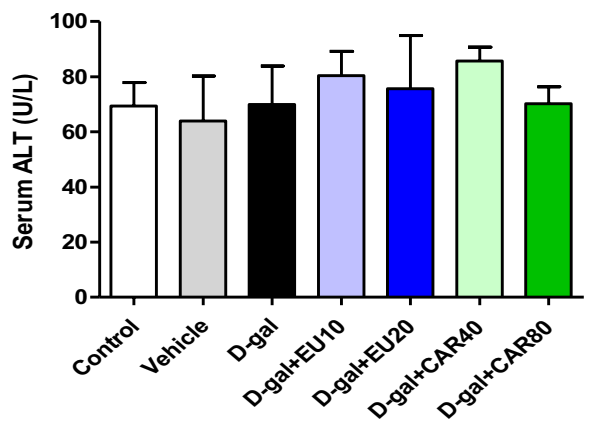

(D)
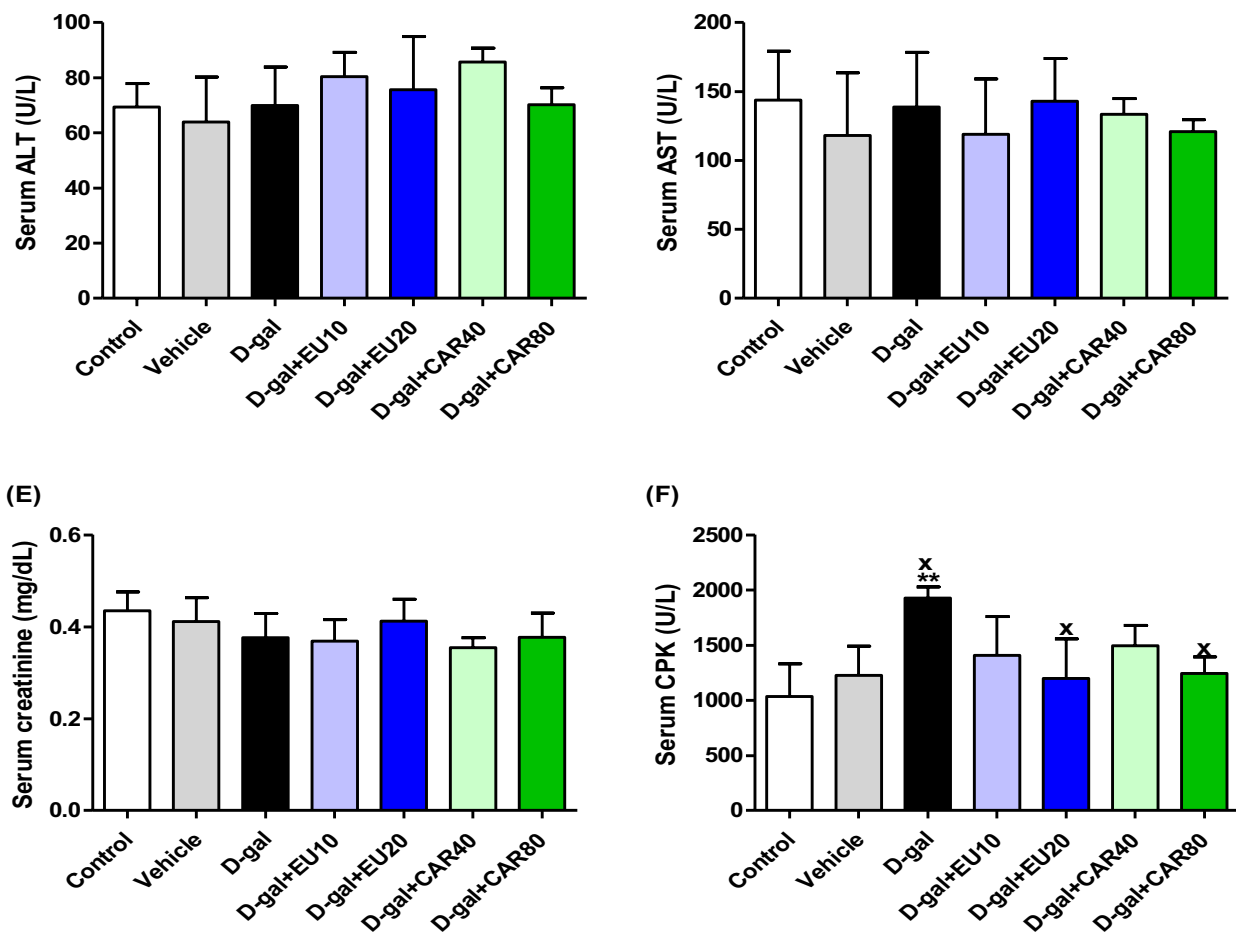

(F)

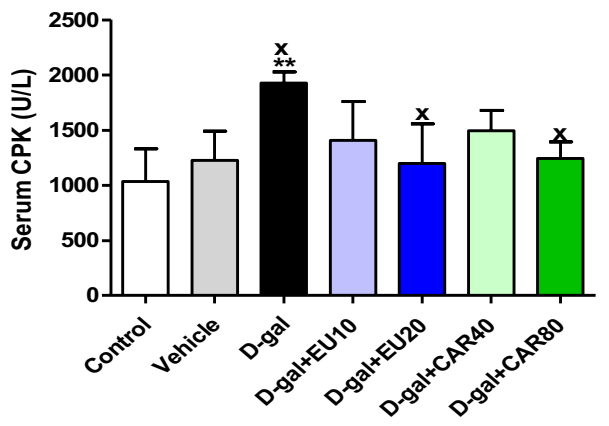

(G)

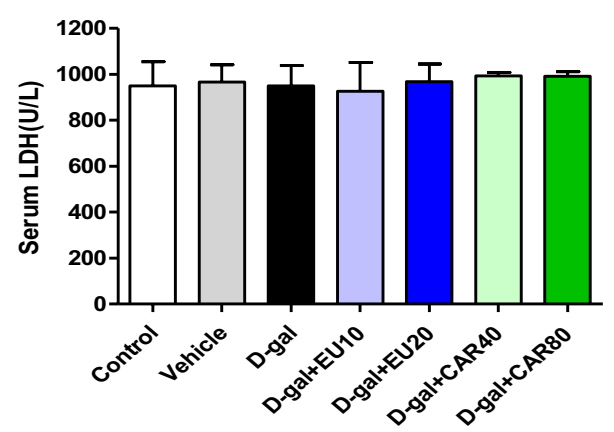

and D-gal+CAR80 groups, the brain Bax mRNA expression levels were significantly decreased $(P<0.001)$ in comparison with the D-gal and vehicle group. The D-gal+EU10 group showed a markedly raised $(P<0.05)$ expression level compared with the D-gal+EU20 group. Also, in the D-gal+EU10 group, its levels were significantly increased $(P$ $<0.001$ ) compared with the D-gal+CAR40 group (Fig. 4C). 
Fig. 3 Oxidative stress and antioxidant status in brain. A Malondialdehyde (MDA), B Total antioxidant capacity (TAC), C Glutathione peroxidase (GPx), and D Glutathione S-transferase (GST). Data were analyzed with a one-way ANOVA followed by Tukey's multiple comparison test. ${ }^{*} P$ $<0.05,{ }^{* *} P<0.01$, and ${ }^{* * *} P<$ 0.001 vs the control. ${ }^{\mathrm{x}} P<0.05$, ${ }^{\mathrm{xx}} P<0.01$, and ${ }^{\mathrm{xxx}} P<0.001$ vs vehicle. ${ }^{+++} P<0.001$ vs D-gal. ${ }^{\phi} P<0.05$ and ${ }^{\phi \Phi} P<0.01$ vs D-gal+EU10. ${ }^{\#} P<0.05$ vs D-gal+CAR40. ${ }^{\theta \theta \theta} P<0.001$ for D-gal+EU10 and D-gal+CAR40 comparison. ${ }^{\Psi \Psi \Psi} P<0.001$ for D-gal+EU20 and D-gal+CAR80 comparison. Error bars represent mean \pm SD. $n=7$.
(A)

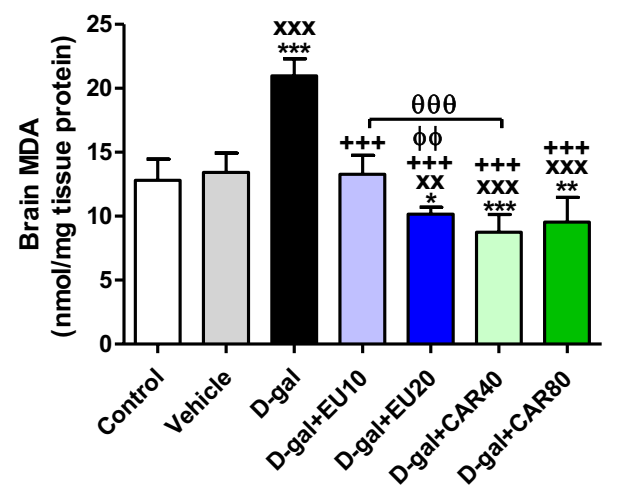

(C)

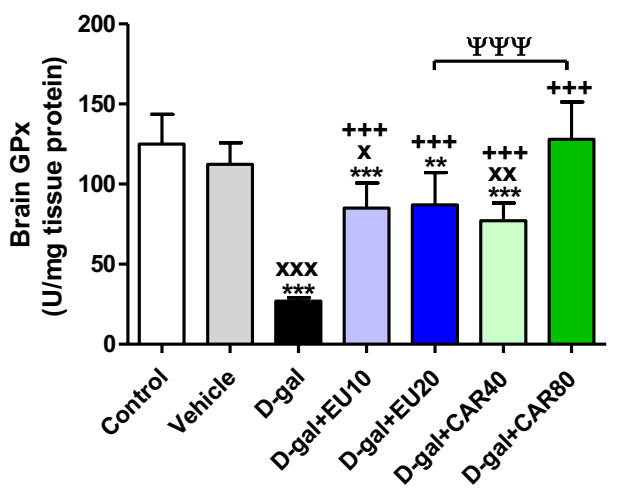

(B)

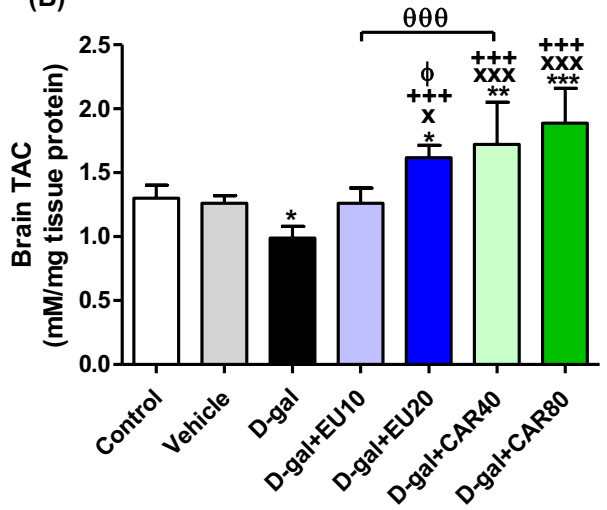

(D)

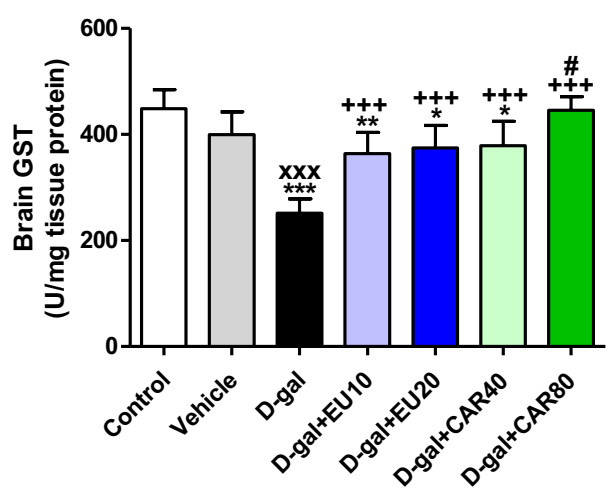

\section{Histopathological assessment}

Negative control and vehicle groups showed a normal cerebellar architecture that consisted of uniform molecular, granular and Purkinje cell layers (Fig. 5A, B). On the other hand, the D-gal group revealed loss and necrosis of Purkinje cells in the Purkinje cells and granular cells layers (Fig. 5C). D-gal+EU10 showed improvement in the number of Purkinje cells in the Purkinje cells layer with a lower number of pyknotic nuclei than the D-gal group (Fig. 5D). D-gal+EU20 and D-gal+CAR40 revealed a relatively normal cerebellar structure as a negative control group (Fig. 5D, F). D-gal+CAR80 showed improvement in the number of Purkinje cells in the Purkinje cells layer with a lower number of pyknotic nuclei than the D-gal group (Fig. 5G).

Negative control and vehicle groups showed normal hippocampal architecture (Fig. 6A, B). On the other hand, the necrosis of dentate gyrus neurons was intensive in the Dgal group. Layers and numbers of hippocampal cells were decreased with enlarged intercellular space and disordered cells; especially, some cells exhibited shrink in volume, with pyknosis or rupture in nuclei (Fig. 6C). D-gal+EU10 showed improvement of hippocampal cells with lower necrosis than the D-gal group (Fig. 6D). D-gal+EU20 revealed a relatively normal hippocampal structure as the negative control group (Fig. 6E). D-gal+CAR40 revealed a relatively normal hippocampal structure as the negative control group (Fig. 6F). D-gal+CAR80 showed improvement of hippocampal cells with lower necrosis than the D-gal group (Fig. 6G).

\section{Discussion}

The percentage of people aged 60 or older was reported to be $12.3 \%$ in 2015 and is predicted to increase to $21.5 \%$ of the world's population by 2050, according to the UN World Population Prospects (Sander et al. 2015). Oxidative stress, a process characterized by the progressive loss of tissue/organ function, is the main inducer of aging (Shwe et al. 2018).

An exogenous dose of D-gal can induce aging effects in several organs by increasing oxidative stress, apoptosis, and inflammation (Rehman et al. 2017; El-Far et al. 2020b). The brain, due to high metabolism, high-fat content, and limited antioxidants protection mechanisms, is the organ most vulnerable to oxidant stress (Çakatay 2010).

In the current study, EU and CAR were significantly attenuated the oxidative stress process in brain homogenates induced by D-gal. EU and CAR significantly increased the activities of GPx and GST, antioxidant enzymes as illustrated in Fig. 7. In the same context, EU induced 


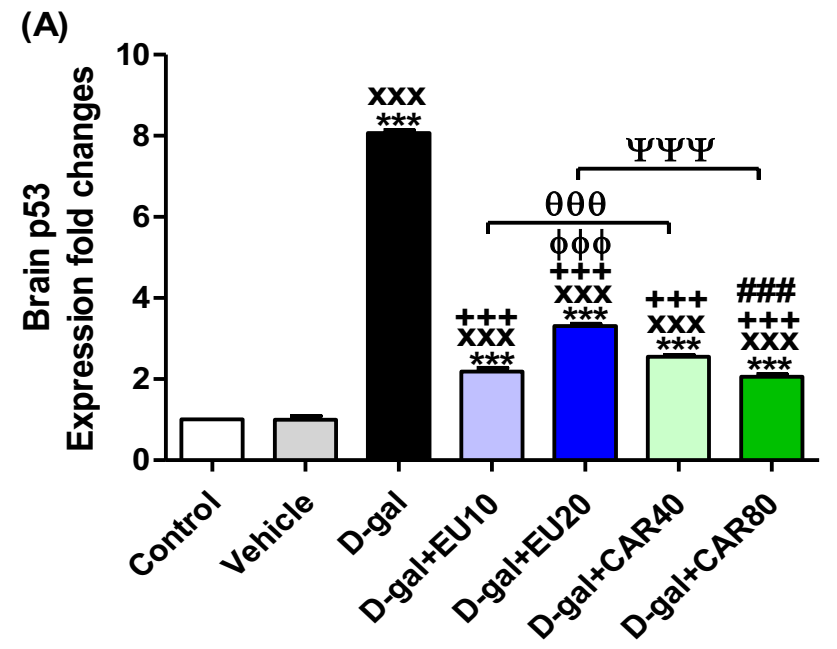

(B)
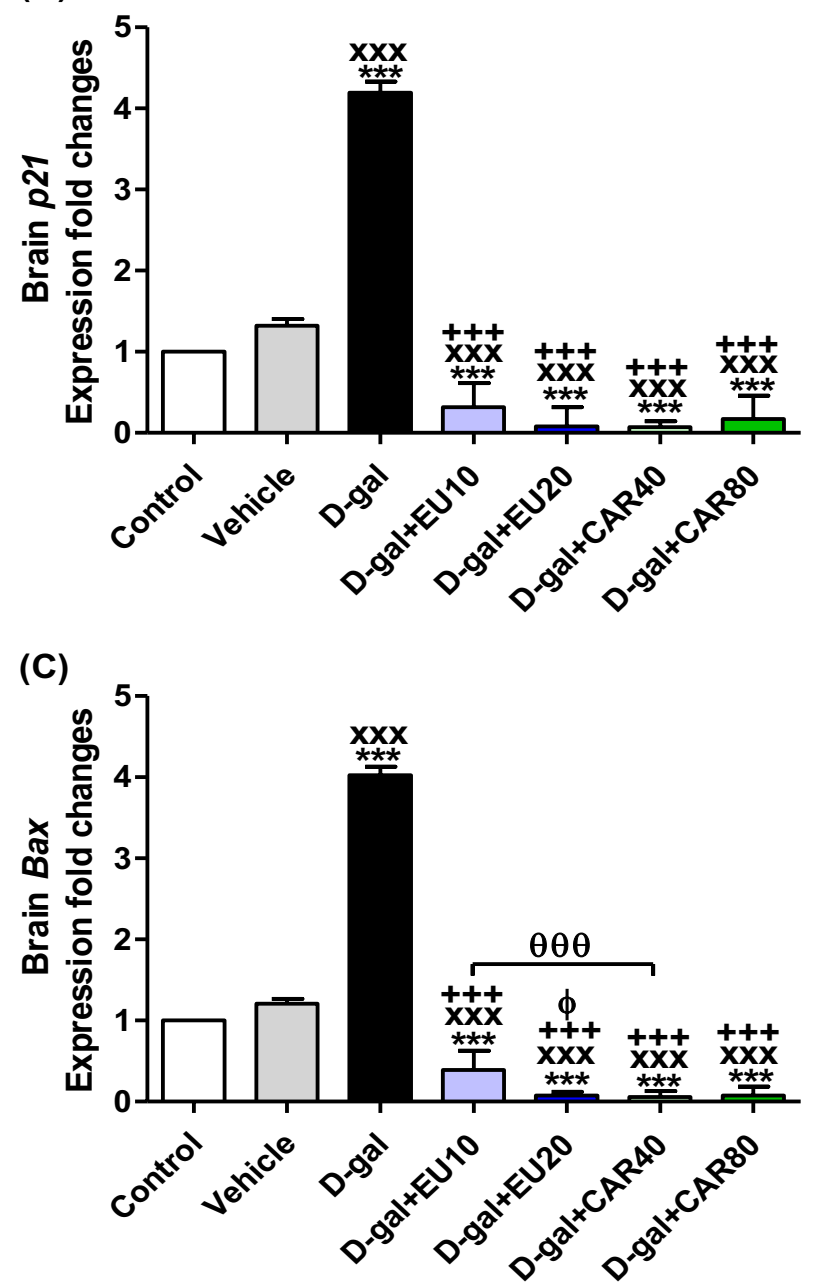

Fig. 4 mRNA relative fold change expression of brain tissue. A p53, B $p 21$, and $\mathbf{C}$ Bcl-2-associated X protein (Bax). Data were analyzed with a one-way ANOVA followed by Tukey's multiple comparison test. ${ }^{* * *} P<0.001$ vs the control. ${ }^{\mathrm{xxx}} P<0.001$ vs Vehicle. ${ }^{+++} P$ $<0.001$ vs D-gal. ${ }^{\Phi} P<0.05$ and ${ }^{\phi} \phi{ }{ }_{P}<0.001$ vs D-gal+EU10. ${ }^{\# \# \# P}<0.001$ vs D-gal+CAR40. ${ }^{\theta \theta} P<0.001$ for D-gal+EU10 and D-gal+CAR40 comparison. ${ }^{\Psi \Psi \Psi} P<0.001$ for D-gal+EU20 and D-gal+CAR80 comparison. Error bars represent mean \pm SD. $n=4$.

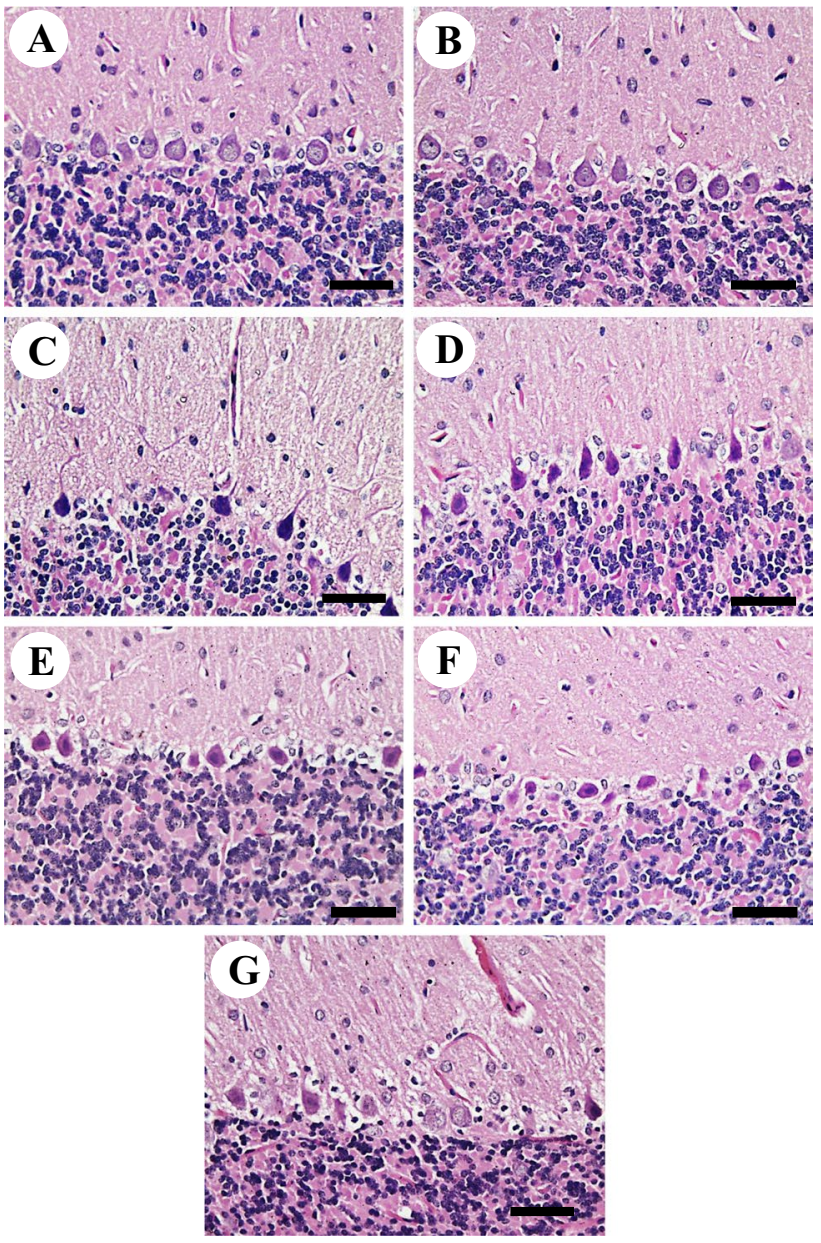

Fig. 5 Histopathological examination of rats' cerebellum. A Control. B Vehicle group. C D-gal group revealing necrosis of Purkinje cells in Purkinje cells layer. D D-gal+EU10. E D-gal+EU20. F D-gal+CAR40. G D-gal+CAR80. Scale bar $=50 \mu \mathrm{m}$.

neuroprotective potential against aluminum-induced oxidative stress by enhancing GPx activity (Mesole et al. 2020). In addition, combining acupuncture and eugenol enhanced learning-memory ability and antioxidation system of hippocampus in Alzheimer's disease rats (Liu et al. 2013). Also, CAR protected against aluminum-induced oxidative stress (Baranauskaite et al. 2020) and Parkinson's disease (Manouchehrabadi et al. 2020) through enhancement of antioxidant enzymes activities.

The D-gal causes a significant decrease in body weight when comparing the D-gal group with the control group. Numerous studies of experimentally induced aging reported that the D-gal decreased the body weight in rats (Chen et al. 2018) and mice (Suo et al. 2018). The current study showed that either EU or CAR administration to rats treated with Dgal could significantly restore body weight to near normal during the treatment period ( 42 days). This observation is supported by the study of Harb et al. (2019) that showed this 


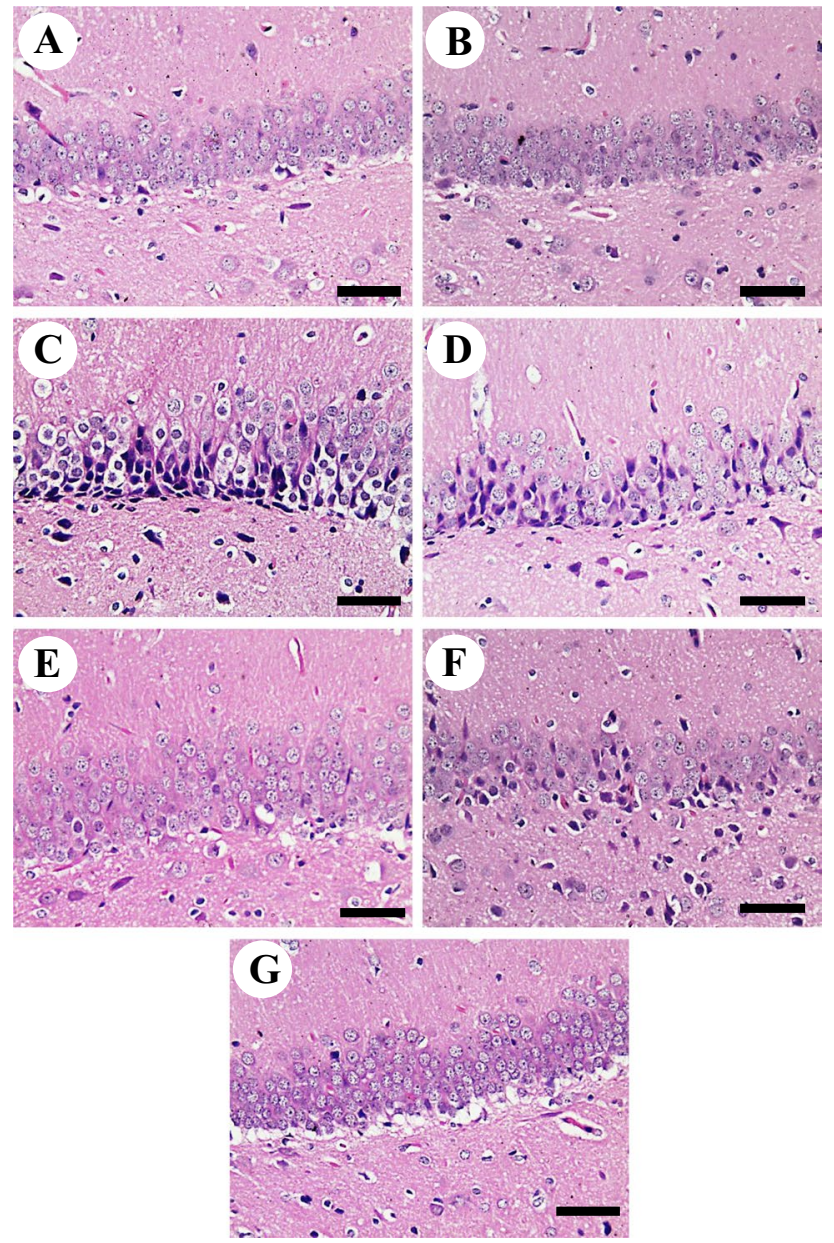

Fig. 6 Histopathological examination of rats' hippocampus. A control group. $\mathbf{B}$ vehicle group. $\mathbf{C}$ D-gal group revealing the necrosis of dentate gyrus neurons. Layers and numbers of hippocampal cells were decreased with enlarged intercellular space and disordered cells; especially, some cells exhibited shrink in volume, with pyknosis or rupture in nuclei. D D-gal+EU10. E D-gal+EU20. F D-gal+CAR40. G D-gal+CAR80. Scale bar $=50 \mu \mathrm{m}$.

improvement in body weight gain in rats by a dose of $10 \mathrm{mg}$ EU per kg B.W. Mohammadi et al. (2014) stated that EU of the clove essential oil could stimulate the proliferation and growth of Lactobacillus that causes changes in villi of the small intestine and effectively improve broiler growth performance. Also, CAR in increasing the animal performance as in Wister rats (Rajan et al. 2015), broiler (Hashemipour et al. 2013), and juvenile rainbow trout (Ahmadifar et al. 2011).

According to the biochemical level, a notable reduction was observed in the serum cholesterol levels of treated groups with either EU or CAR. This could be due to their hypocholesterolemic activity of them. All doses of either EU or CAR cause a reduction in the serum total TAG levels when orally administered to the D-gal-treated group daily 42 days, although this decrease was not high. Elbahy et al.
(2015) and Karam et al. (2015) confirmed our findings that EU and CAR reduced serum TAG and cholesterol levels.

As a response to the DNA damage, p53 becomes functionally active. It initiates either a reversible cell cycle arrest, cell death (apoptosis), or irreversible cell cycle arrest (cellular senescence), leading to aging (Rodier et al. 2007). p53 regulates a complex antiproliferative transcriptional program that is related to senescence, which induces the transcription of the cyclin-dependent kinase inhibitor (CDKi) p21 (Macip et al. 2002), which blocks CDK2 activity, resulting in cell cycle exit (Herranz and Gil 2018).

According to the molecular level, this study showed the effect of D-gal injection on the brain $p 53$ and $p 21$ mRNA expression levels. There was a significant elevation in the brain $p 53$ and $p 21$ mRNA expression in response to the $\mathrm{D}-$ gal injection. El-Far et al. (2020a) recognized significant upregulations of $p 53$ and $p 21$ expressions in D-gal treated rats. Also, Sun et al. (2018) declared an upregulation of $p 21$ upregulation in mice injected with D-gal. D-gal causes oxidative stress at high levels via the accumulation of ROS, stimulates free radical production, and reduces antioxidant enzyme activities (Xu et al. 2009). Oxidative damage and inflammation play critical roles in mediating the age-related alterations in different organs such as the brain, muscle, and kidney (Wei et al. 2005).

The current results showed significant decreases in the brain p53 mRNA expression in EUR- and CAR-treated groups than the D-gal group, but its levels were still higher than the control groups. As for the brain, $p 21$ and Bax mRNA expression levels were significantly decreased in EUR- and CAR-treated groups than control and D-gal groups. D-gal induces senescence of glioblastoma cells with upregulation of $p 53$ (Xu et al. 2020). Liu et al. (2018) recognized the upregulation of $p 53$ and $p 21$ in the hippocampus of mice treated with D-gal. Also, D-gal induced significant elevations in $p 53, p 21$, and Bax in rats' pancreas and kidneys (El-Far et al. 2020b).

Manikandan et al. (2010, 2011) reported that the administration of EU induced apoptosis via the mitochondrial pathway by modulating the Bcl-2 family proteins, while according to the CAR, Potočnjak and Domitrović (2016) stated its role in decreasing the expression of $p 53$ and $p 21$ expressions against cisplatin-induced toxicity in mice.

In the present study, Bax mRNA expression level exhibited a significant increase due to the D-gal. In many studies, Shahroudi et al. (2017) and Xu et al. (2016) reported a significant elevation in Bax expression in brain tissues of mice treated with D-gal, while the Bax mRNA expression level exhibited significant decreases in rats treated with EU and CAR. Júnior et al. (2016) demonstrated that the EU promotes Bax overexpression in cervical cancer cells. Shoorei et al. (2019) reported that CAR decreased the Bax expression 
Fig. 7 Eugenol (EU) and carvacrol (CAR) protective potential against oxidative stress induced by D-galactose (D-gal). Bax; Bcl-2-associated $\mathrm{X}$ protein. GPx; glutathione peroxidase. GST; glutathione S-transferase. MDA; malondialdehyde. TAC; total antioxidant capacity.
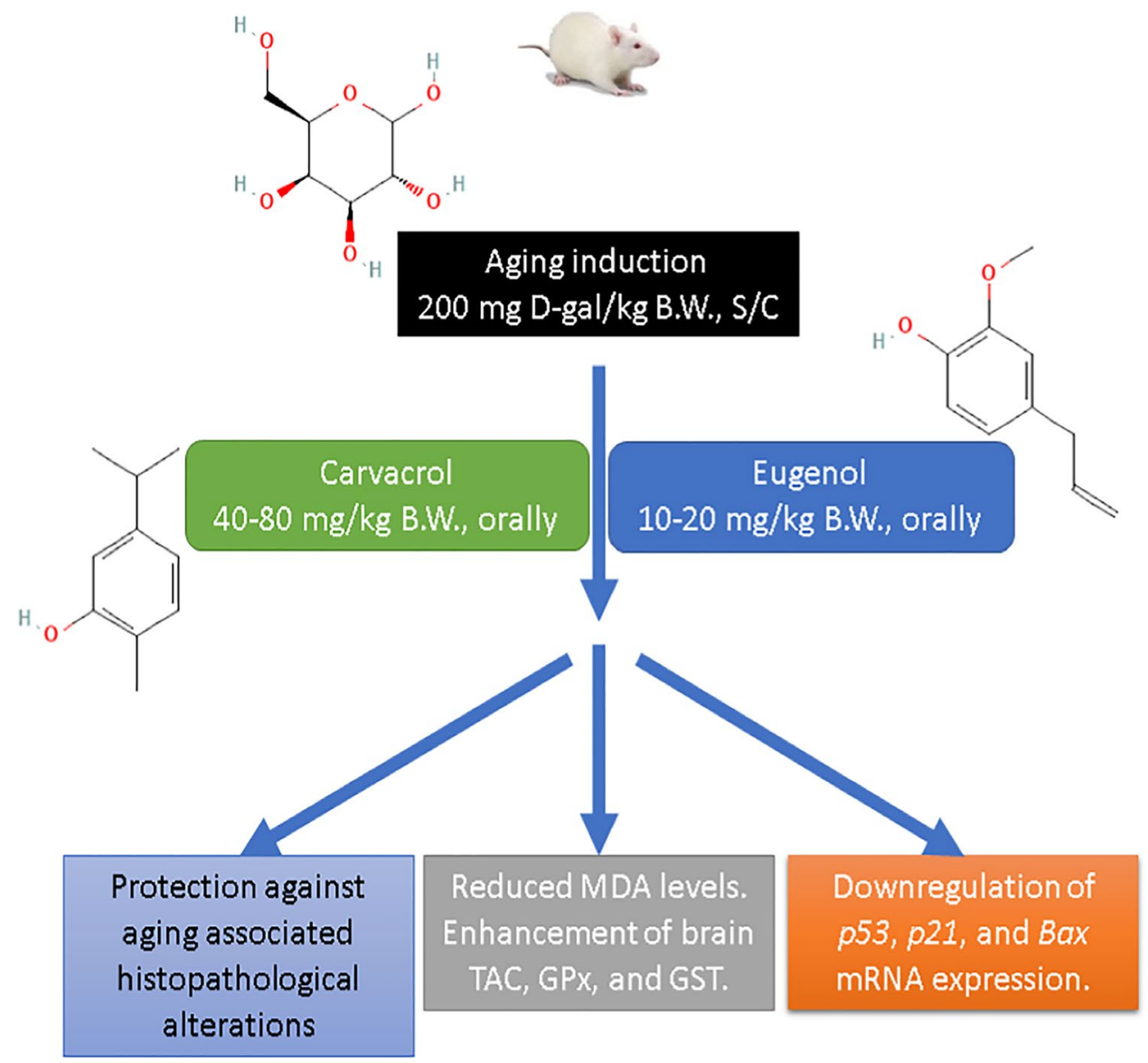

in testicular tissue of adult diabetic rats. Also, Sadeghzadeh et al. (2018) mentioned that the Bax expression reduced by the effect of CAR in the hypertrophied heart in rats.

In the current study, D-gal induced necrosis of Purkinje cells in Purkinje cells layer of rats' cerebellum and necrosis of dentate gyrus neurons hippocampus. In contrast, these necroses were defeated in EU- and CAR-supplemented groups. Chiroma et al. (2018) stated that D-gal and aluminum chloride-induced marked neuronal loss in rats' hippocampus.

Regarding the protective effects of the EU and CAR against the histopathological changes in the cerebellum and hippocampus, the present study is considered the first recognized significant alleviation in the brain's histopathological changes.

\section{Conclusion}

The oxidative stress hypothesis remains possibly the basis of aging-associated cellular alterations. EU and CAR in a dosedependent manner potentially attenuated the oxidative stress induced by D-gal in the brain tissues of rats through downregulation of aging markers ( $p 53$ and $p 21$ ) and apoptotic marker (Bax) with an enhancement of the antioxidant status of brain tissues. Our results suggest that the EU and CAR successfully alleviated the aging of rats' brain tissues, rendering them promising natural anti-aging supplements.

Author contribution Conceptualization: Ali H. El-Far, Hadeer H. Mohamed, Doaa A. Elsabagh, Shymaa A. Mohamed, Ahmed E. Noreldin, Soad Al Jaouni, and Abdelwahab ElSenosy; formal analysis: Ali H. El-Far, Hadeer H. Mohamed, Doaa A. Elsabagh, Shymaa A. Mohamed, Ahmed E. Noreldin, Soad Al Jaouni, and Abdelwahab ElSenosy; investigation: Ali H. El-Far, Hadeer H. Mohamed, Doaa A. Elsabagh, Shymaa A. Mohamed, Ahmed E. Noreldin, and Abdelwahab ElSenosy; software: Ali H. El-Far, Hadeer H. Mohamed, and Doaa A. Elsabagh; validation: Ali H. El-Far, Hadeer H. Mohamed, Doaa A. Elsabagh, Shymaa A. Mohamed, Ahmed E. Noreldin, Soad Al Jaouni, and Abdelwahab ElSenosy; visualization: Ali H. El-Far, Hadeer H. Mohamed, Doaa A. Elsabagh, Shymaa A. Mohamed, Ahmed E. Noreldin, and Abdelwahab ElSenosy; writing —original draft: Ali H. El-Far, Hadeer H. Mohamed, Doaa A. Elsabagh, and Shymaa A. Mohamed; writing-review and editing: Ali H. El-Far, Hadeer H. Mohamed, Doaa A. Elsabagh, Shymaa A. Mohamed, Ahmed E. Noreldin, Soad Al Jaouni, and Abdelwahab ElSenosy.

Funding Open access funding provided by The Science, Technology \& Innovation Funding Authority (STDF) in cooperation with The Egyptian Knowledge Bank (EKB). 
Data availability All data generated or analyzed during this study are included in this published article.

\section{Declarations}

Ethical approval The study was approved by the Faculty of Veterinary Medicine Ethics Committee of Damanhour University, Egypt, following "NIH Guide for the Care and Use of Laboratory Animals" guidelines.

\section{Consent to participate Not applicable.}

Consent to publish All the authors approved the final manuscript and agreed to its publication in the Environmental Science and Pollution Research.

Competing interests The authors declare no competing interests.

Open Access This article is licensed under a Creative Commons Attribution 4.0 International License, which permits use, sharing, adaptation, distribution and reproduction in any medium or format, as long as you give appropriate credit to the original author(s) and the source, provide a link to the Creative Commons licence, and indicate if changes were made. The images or other third party material in this article are included in the article's Creative Commons licence, unless indicated otherwise in a credit line to the material. If material is not included in the article's Creative Commons licence and your intended use is not permitted by statutory regulation or exceeds the permitted use, you will need to obtain permission directly from the copyright holder. To view a copy of this licence, visit http://creativecommons.org/licenses/by/4.0/.

\section{References}

Abadi AJ, Mirzaei S, Mahabady MK et al (2021) Curcumin and its derivatives in cancer therapy: potentiating antitumor activity of cisplatin and reducing side effects. Phyther Res n/a. https://doi. org/10.1002/ptr.7305

Acosta PB, Gross KC (1995) Hidden sources of galactose in the environment. Eur J Pediatr 154:S87-S92. https://doi.org/10.1007/ BF02143811

Ahmadifar E, Falahatkar B, Akrami R (2011) Effects of dietary thymol-carvacrol on growth performance, hematological parameters and tissue composition of juvenile rainbow trout, Oncorhynchus mykiss. J Appl Ichthyol 27:1057-1060. https://doi.org/10.1111/j. 1439-0426.2011.01763.x

Aristatile B, Al-Numair KS, Veeramani C, Pugalendi KV (2009) Effect of carvacrol on hepatic marker enzymes and antioxidant status in d-galactosamine-induced hepatotoxicity in rats. Fundam Clin Pharmacol 23:757-765. https://doi.org/10.1111/j.1472-8206. 2009.00721.x

Ashrafizadeh M, Zarrabi A, Hashemi F et al (2020) Curcumin in cancer therapy: a novel adjunct for combination chemotherapy with paclitaxel and alleviation of its adverse effects. Life Sci 256:117984. https://doi.org/10.1016/j.1fs.2020.117984

Ashrafizadeh M, Rafiei H, Mohammadinejad R et al (2021) Anti-tumor activity of resveratrol against gastric cancer: a review of recent advances with an emphasis on molecular pathways. Cancer Cell Int 21:66. https://doi.org/10.1186/s12935-021-01773-7
Atanasov AG, Zotchev SB, Dirsch VM et al (2021) Natural products in drug discovery: advances and opportunities. Nat Rev Drug Discov 20:200-216

Bancroft J, Layton C (2013) The Hematoxylin and eosin. In: Suvarna SK, Layton C, Bancroft JD (eds) Theory Practice of histological techniques, 7th ed edn. Churchill Livingstone of El Sevier, Philadelphia

Baranauskaite J, Sadauskiene I, Liekis A et al (2020) Natural compounds rosmarinic acid and carvacrol counteract aluminiuminduced oxidative stress. Molecules 25:1807. https://doi.org/10. 3390/molecules25081807

Bradford MM (1976) A rapid and sensitive method for the quantitation of microgram quantities of protein utilizing the principle of protein-dye binding. Anal Biochem 72:248-254

Bucala R, Cerami A (1992) Advanced glycosylation: chemistry, biology, and implications for diabetes and aging. Adv Pharmacol 23:1-34. https://doi.org/10.1016/S1054-3589(08)60961-8

Çakatay U (2010) Protein redox-regulation mechanisms in aging. In: Aging and Age-Related Disorders. Humana Press, New York, pp $3-25$

Chen P, Chen F, Zhou B (2018) Antioxidative, anti-inflammatory and anti-apoptotic effects of ellagic acid in liver and brain of rats treated by D-galactose. Sci Rep 8:1465. https://doi.org/10.1038/ s41598-018-19732-0

Chiroma SM, Mohd Moklas MA, Mat Taib CN et al (2018) D-galactose and aluminium chloride induced rat model with cognitive impairments. Biomed Pharmacother 103:1602-1608. https://doi. org/10.1016/j.biopha.2018.04.152

Coelho AI, Berry GT, Rubio-Gozalbo ME (2015) Galactose metabolism and health. Curr Opin Clin Nutr Metab Care 18:422-427

Davalli P, Mitic T, Caporali A et al (2016) ROS, Cell senescence, and novel molecular mechanisms in aging and age-related diseases. Oxidative Med Cell Longev 2016:1-18. https://doi.org/10.1155/ 2016/3565127

Elbahy DA, Madkour HI, Abdel-Raheem MH (2015) Evaluation of antihyperlipidemic activity of eugenol in triton induced hyperlipidemia in rats. Int J Res Stud Biosci 3:19-26

El-Far AH (2015) Thymoquinone anticancer discovery: possible mechanisms. Curr Drug Discov Technol 12:80-89. https://doi.org/10. 2174/1570163812666150716111821

El-Far AH, Al Jaouni SK, Li W, Mousa SA (2018) Protective roles of thymoquinone nanoformulations: potential nanonutraceuticals in human diseases. Nutrients 10:1369. https://doi.org/10.3390/ nu10101369

El-Far AH, Darwish NHEE, Mousa SA (2020a) Senescent colon and breast cancer cells induced by doxorubicin exhibit enhanced sensitivity to curcumin, caffeine, and thymoquinone. Integr Cancer Ther 19:1534735419901160. https://doi.org/10.1177/1534735419 901160

El-Far AH, Lebda MA, Noreldin AE et al (2020b) Quercetin attenuates pancreatic and renal D-galactose-induced aging-related oxidative alterations in rats. Int J Mol Sci 21:4348. https://doi.org/10.3390/ ijms 21124348

El-Far AH, Godugu K, Noreldin AE et al (2021) Thymoquinone and costunolide induce apoptosis of both proliferative and doxorubicin-induced-senescent colon and breast cancer cells. Integr Cancer Ther 20:15347354211035450. https://doi.org/10.1177/ 15347354211035450

Fan J, Yang X, Li J et al (2017) Spermidine coupled with exercise rescues skeletal muscle atrophy from $\mathrm{D}$-gal-induced aging rats through enhanced autophagy and reduced apoptosis via AMPKFOXO3a signal pathway. Oncotarget 8:17475-17490. https://doi. org/10.18632/oncotarget.15728 
Gross KC, Acosta PB (1991) Fruits and vegetables are a source of galactose: implications in planning the diets of patients with Galactosaemia. J Inherit Metab Dis 14:253-258. https://doi.org/ 10.1007/BF01800599

Gülçin I (2011) Antioxidant activity of eugenol: a structure-activity relationship study. J Med Food 14:975-985. https://doi.org/10. 1089/jmf.2010.0197

Harb AA, Bustanji YK, Almasri IM, Abdalla SS (2019) Eugenol reduces LDL cholesterol and hepatic steatosis in hypercholesterolemic rats by modulating TRPV1 receptor. Sci Rep 9:14003. https://doi.org/10.1038/s41598-019-50352-4

Hashemipour H, Kermanshahi H, Golian A, Veldkamp T (2013) Metabolism and nutrition: effect of thymol and carvacrol feed supplementation on performance, antioxidant enzyme activities, fatty acid composition, digestive enzyme activities, and immune response in broiler chickens. Poult Sci 92:2059-2069. https://doi. org/10.3382/ps.2012-02685

Herranz N, Gil J (2018) Mechanisms and functions of cellular senescence. J Clin Invest 128:1238-1246. https://doi.org/10.1172/JCI95 148

Júnior PLDS, Câmara DAD, Costa AS et al (2016) Apoptotic effect of eugenol envolves G2/M phase abrogation accompanied by mitochondrial damage and clastogenic effect on cancer cell in vitro. Phytomedicine 23:725-735. https://doi.org/10.1016/j.phymed. 2016.03.014

Karam I, Ma N, Liu X-W et al (2015) Regulation effect of Aspirin Eugenol Ester on blood lipids in Wistar rats with hyperlipidemia. BMC Vet Res 11:217. https://doi.org/10.1186/s12917-015-0523-5

Krafts KP (2010) Tissue repair: The hidden drama. Organogenesis 6(4):225-233

Liu Z, Niu W, Yang X, Wang Y (2013) Effects of combined acupuncture and eugenol on learning-memory ability and antioxidation system of hippocampus in Alzheimer disease rats via olfactory system stimulation. J Tradit Chin Med 33:399-402. https://doi. org/10.1016/S0254-6272(13)60186-7

Liu C, Sun W, Li N et al (2018) Schisantherin a improves learning and memory of mice with D-Galactose-induced learning and memory impairment through its antioxidation and regulation of p19/p53/ p21/Cyclin D1/CDK4/RB Gene Expressions. J Med Food 21:678688. https://doi.org/10.1089/jmf.2017.4090

Livak KJ, Schmittgen TD (2001) Analysis of relative gene expression data using real-time quantitative PCR and the $2-\Delta \Delta C$ T method. Methods 25:402-408. https://doi.org/10.1006/meth.2001.1262

Macip S, Igarashi M, Fang L et al (2002) Inhibition of p21-mediated ROS accumulation can rescue p21-induced senescence. EMBO J 21:2180-2188. https://doi.org/10.1093/emboj/21.9.2180

Manikandan P, Murugan RS, Priyadarsini RV et al (2010) Eugenol induces apoptosis and inhibits invasion and angiogenesis in a rat model of gastric carcinogenesis induced by MNNG. Life Sci 86:936-941. https://doi.org/10.1016/j.lfs.2010.04.010

Manikandan P, Vinothini G, Vidya Priyadarsini R et al (2011) Eugenol inhibits cell proliferation via NF- $\mathrm{KB}$ suppression in a rat model of gastric carcinogenesis induced by MNNG. Investig New Drugs 29:110-117. https://doi.org/10.1007/s10637-009-9345-2

Manouchehrabadi M, Farhadi M, Azizi Z, Torkaman-Boutorabi A (2020) Carvacrol protects against 6-hydroxydopamine-induced neurotoxicity in in vivo and in vitro models of Parkinson's disease. Neurotox Res 37:156-170. https://doi.org/10.1007/ s12640-019-00088-w

Mateen S, Shahzad S, Ahmad S et al (2019) Cinnamaldehyde and eugenol attenuates collagen induced arthritis via reduction of free radicals and pro-inflammatory cytokines. Phytomedicine 53:70-78. https://doi.org/10.1016/J.PHYMED.2018.09.004
Mesole SB, Alfred OO, Yusuf UA et al (2020) Apoptotic inducement of neuronal cells by aluminium chloride and the neuroprotective effect of eugenol in Wistar rats. Oxidative Med Cell Longev 2020:1-7. https://doi.org/10.1155/2020/8425643

Mohammadi Z, Ghazanfari S, Adib Moradi M (2014) Einfluss eines Zusatzes von essentiellen ölen der nelke zum futter auf die mikroflora und die morphologie im darm sowie auf blutparameter und leistung von broilern. Eur Poult Sci 78:1-11. https://doi.org/ 10.1399/eps.2014.51

Mohsen E, El-Far AH, Godugu K et al (2022) SPME and solvent-based GC-MS metabolite profiling of Egyptian marketed Saussurea costus (Falc.) Lipsch. concerning its anticancer activity. Phytomed Plus 2:100209. https://doi.org/10.1016/j.phyplu.2021.100209

Mondal A, Bose S, Mazumder K, Khanra R (2021) Carvacrol (Origanum vulgare): Therapeutic Properties and Molecular Mechanisms. In: Advanced Structured Materials. Springer Science and Business Media Deutschland GmbH, Berlin, pp 437-462

Neki NS (2015) Oxidative stress and aging. Bangladesh J Med Sci $14: 221-227$

Parameshwaran K, Irwin MH, Steliou K, Pinkert CA (2010) D-galactose effectiveness in modeling aging and therapeutic antioxidant treatment in mice. Rejuvenation Res 13:729-735. https://doi.org/ 10.1089/rej.2010.1020

Potočnjak I, Domitrović R (2016) Carvacrol attenuates acute kidney injury induced by cisplatin through suppression of ERK and PI3K/ Akt activation. Food Chem Toxicol 98:251-261. https://doi.org/ 10.1016/j.fct.2016.11.004

Rajan B, Ravikumar R, Premkumar T, Devaki T (2015) Carvacrol attenuates $\mathrm{N}$-nitrosodiethylamine induced liver injury in experimental Wistar rats. Food Sci Human Wellness 4:66-74. https:// doi.org/10.1016/j.fshw.2015.04.002

Rehman SU, Shah SA, Ali T et al (2017) Anthocyanins reversed D-galactose-induced oxidative stress and neuroinflammation mediated cognitive impairment in adult rats. Mol Neurobiol 54:255-271. https://doi.org/10.1007/s12035-015-9604-5

Rodier F, Campisi J, Bhaumik D (2007) Two faces of p53: Aging and tumor suppression. Nucleic Acids Res 35:7475-7484. https://doi. org/10.1093/nar/gkm744

Sadeghzadeh S, Hejazian SH, Jamhiri M et al (2018) The effect of carvacrol on transcription levels of Bcl-2 family proteins in hypertrophied heart of rats. Physiol Pharmacol 22:54-62

Sander M, Oxlund B, Jespersen A et al (2015) The challenges of human population ageing. Age Ageing 44:185-187. https://doi.org/10. 1093/ageing/afu189

Shahroudi MJ, Mehri S, Hosseinzadeh H (2017) Anti-aging effect of nigella sativa fixed oil on d-galactose-induced aging in mice. Aust J Pharm 20:29-35. https://doi.org/10.3831/KPI.2017.20.006

Sharifi-Rad M, Varoni EM, Iriti M et al (2018) Carvacrol and human health: a comprehensive review. Phyther Res 32:1675-1687

Shoorei H, Khaki A, Khaki AA et al (2019) The ameliorative effect of carvacrol on oxidative stress and germ cell apoptosis in testicular tissue of adult diabetic rats. Biomed Pharmacother 111:568-578. https://doi.org/10.1016/j.biopha.2018.12.054

Shwe T, Pratchayasakul W, Chattipakorn N, Chattipakorn SC (2018) Role of D-galactose-induced brain aging and its potential used for therapeutic interventions. Exp Gerontol 101:13-36

Song X, Bao M, Li D, Li YM (1999) Advanced glycation in D-galactose induced mouse aging model

Stojanović NM, Stevanović M, Randjelović P et al (2019) Low dose of carvacrol prevents rat pancreas tissue damage after L-arginine application, while higher doses cause pancreatic tissue impairment. Food Chem Toxicol 128:280-285. https://doi.org/10.1016/J. FCT.2019.04.010 
Sun K, Yang P, Zhao R et al (2018) Matrine Attenuates D-galactoseinduced aging-related behavior in mice via inhibition of cellular senescence and oxidative stress. Oxidative Med Cell Longev 2018:1-12. https://doi.org/10.1155/2018/7108604

Suo H, Liu S, Li J et al (2018) Lactobacillus paracasei ssp. paracasei YBJ01 reduced D-galactose-induced oxidation in male Kuming mice. J Dairy Sci 101:10664-10674. https://doi.org/10.3168/jds. 2018-14758

Wei H, Li L, Song Q et al (2005) Behavioural study of the D-galactose induced aging model in C57BL/6J mice. Behav Brain Res 157:245-251. https://doi.org/10.1016/j.bbr.2004.07.003

Williams CA (2003) GALACTOSE. In: Encyclopedia of Food Sciences and Nutrition. Elsevier, Oxford, pp 2843-2846

Xu Y, Wu T, Jin Y, Fu Z (2009) Effects of age and jet lag on d-galactose induced aging process. Biogerontology 10:153-161. https://doi. org/10.1007/s10522-008-9158-2
Xu LQ, Xie YL, Gui SH et al (2016) Polydatin attenuates d-galactose-induced liver and brain damage through its anti-oxidative, anti-inflammatory and anti-apoptotic effects in mice. Food Funct 7:4545-4555. https://doi.org/10.1039/c6fo01057a

Xu X, Shen X, Feng W et al (2020) D-galactose induces senescence of glioblastoma cells through YAP-CDK6 pathway. Aging (Albany NY) 12:18501-18521. https://doi.org/10.18632/aging.103819

Yogalakshmi B, Viswanathan P, Anuradha CV (2010) Investigation of antioxidant, anti-inflammatory and DNA-protective properties of eugenol in thioacetamide-induced liver injury in rats. Toxicology 268:204-212. https://doi.org/10.1016/J.TOX.2009.12.018

Publisher's note Springer Nature remains neutral with regard to jurisdictional claims in published maps and institutional affiliations. 